\title{
RESPONSABILIDADE CIVIL AMBIENTAL E A MINERAÇÃO NO BRASIL: ANÁLISE DA NECESSIDADE DE PROTEÇÃO AMBIENTAL, REINVENÇÃO DAS ATIVIDADES ECONÔMICAS E O EVENTUAL PARADOXO COM A ATIVIDADE MINERÁRIA
}

\author{
Camila Martins de Oliveira ${ }^{1}$ \\ Luciana Machado Teixeira Fabel ${ }^{2}$
}

Resumo: O presente artigo tem como objetivo demonstrar que a mineração no Brasil precisa se modificar para atender aos requisitos impostos pela legislação ambiental. A atividade extrativa mineral é de suma importância para o país e corresponde a $4 \%$ do PIB, além de gerar 180 mil empregos diretos. A partir da análise da legislação, doutrina e jurisprudência, promoveu-se um raciocínio crítico-dedutivo, concluindo que a possibilidade de uma convivência harmônica entre mineração e preservação ambiental constitui o futuro deste importante setor da economia mundial.

Palavras-chave: Mineração; Legislação ambiental; Desenvolvimento econômico; Preservação ambiental; Responsabilidade civil.

\section{ENVIRONMENTAL RESPONSIBILITY AND MINING IN BRAZIL: ANALYSIS OF THE NEED FOR ENVIRONMENTAL PROTECTION, REINVENTION OF ECONOMIC ACTIVITIES AND THE POSSIBLE PARADOX WITH MINING ACTIVITY}

\begin{abstract}
This article aims to demonstrate that mining in Brazil needs to be modified to meet the requirements imposed by environmental legislation. Mining and quarrying is of major importance to the country and corresponds to 4\% of GDP, besides generating 180 thousand direct jobs. From the analysis of legislation, doctrine and jurisprudence, a critical-deductive reasoning was promoted, concluding that the possibility of harmonious coexistence between mining and environmental preservation constitutes the future of this important sector of the world economy.
\end{abstract}

Keywords: Mining; Environmental legislation; Economic development; Environmental preservation; Civil responsability.

\footnotetext{
${ }^{1}$ Doutoranda em Direito pela Escola Superior Dom Helder Câmara; Mestre em Direito pela Escola Superior Dom Helder Câmara; Especialista em Direito Público pela Centro de Estudos em Direito e Universidade Gama Filho; Bacharel em Direito pela Pontifícia Universidade Católica de Minas Gerias - PUC/Minas; Professora de Direito Penal e Legislação Penal Especial da Escola Superior Do Helder Câmara; Advogada. E-mail: camartinsoliveira1@gmail.com

${ }^{2}$ Doutoranda em Direito pela Escola Superior Dom Helder Câmara (DHC); Mestre em Administração; Especialista em Direito Público; Graduada em Direito pela Faculdade Milton Campos; Advogada. E-mail: lucianamt@bol.com.br
} 


\section{INTRODUÇÃO}

O problema que se enfrentará consiste em demonstrar que existem métodos que não degradam tanto o meio ambiente e que se utilizados pelas empresas do setor de mineração poderão favorecer o setor mineral e o meio ambiente.

O tema central que se abordará é a discussão da possibilidade de existir uma convivência harmônica entre a exploração mineral e a preservação ambiental.

O objetivo que se espera atingir é a demonstração de que a adoção de melhores técnicas para a exploração mineral poderá, além de mitigar os riscos desta atividade, trazer benefícios ao meio ambiente e à sociedade, de forma que transformará uma atividade extremamente poluidora em atividade sustentável.

Justifica-se este estudo na medida em que a mineração constitui um setor de suma importância para o desenvolvimento econômico e social do Brasil e do mundo, e a privação da atividade extrativa mineral traria sérias consequências para a sociedade.

Os métodos de pesquisa consistem no estudo comparativo entre a atividade extrativa mineral, o rompimento das barragens de Mariana (2015) e Brumadinho (2019), em Minas Gerais, a importância da mineração para o desenvolvimento econômico e social e a preservação ambiental, que poderão contribuir para responder aos seguintes questionamentos: É possível uma convivência harmônica entre a mineração e a preservação ambiental? Qual a postura que os empresários e o Poder Público terão que adotar para que este equilíbrio seja atingido? Existem métodos de extração mineral que causem menores danos ao meio ambiente? Qual a lição aprendida após o rompimento das barragens de Mariana (2015) e Brumadinho (2019)?

Estabelece-se, assim, o objetivo de investigar possibilidades para que a atividade extrativa mineral cause o menor dano ambiental possível, de forma que se possa ter uma mineração sustentável e que preserve o meio ambiente.

Nas reflexões para responder ao objetivo desse estudo será utilizada a metodologia da pesquisa bibliográfica com raciocínio crítico-dedutivo.

Como referencial teórico na busca de argumentos será usado suporte filosófico em Beck. 
Para uma melhor compreensão do tema, o estudo se inicia com a exposição acerca do surgimento da questão ambiental, para depois abordar a atividade de extração mineral e sua importância socioeconômica.

Em um segundo momento o estudo será sobre a responsabilidade civil ambiental do poder público na mineração e sobre os modelos de barragens de rejeitos e suas características.

Este estudo será finalizado com o modelo de mineração a seco que possibilita o reaproveitamento dos rejeitos como solução para a controvérsia existente entre mineração e preservação ambiental.

\section{O SURGIMENTO DA QUESTÃO AMBIENTAL}

A questão ambiental surgiu no Estado Liberal Democrático de Direito, na segunda metade do século XX, como um dos grandes problemas do Estado Moderno.

Além das questões individual e social, a questão ambiental veio como mais um anseio da população tendo em vista o surgimento de novos problemas como a extinção das espécies, o esgotamento dos recursos naturais, a poluição e a nova tecnologia nuclear.

Acerca desta crise ambiental Beck destaca:

As teorias sociais do século XX (e também suas modificações no século XXI) conceberam a natureza como algo essencialmente predeterminado, designado, a ser subjugado assim, porém, sempre como algo contraposto, estranho, ao social. O próprio processo de industrialização refutou estas suposições, ao mesmo tempo em que as tomou historicamente falsas. No final do século XX, a "natureza" nem é predeterminada e nem designada, tendo-se transformado em produto social e, sob as condições naturais de sua reprodução, na combalida ou ameaçada estrutura interna do universo civilizatório. Todavia, isto implica dizer: destruições da natureza, integradas à circulação universal da produção industrial, deixam de ser "meras" destruições da natureza e passam a ser elemento constitutivo da dinâmica social, econômica e política. (1998, p.98)

Ao longo do desenvolvimento do Estado Moderno alguns marcos históricos se destacam e permitem uma maior compreensão acerca da origem dos problemas ambientais tão presentes atualmente. 
A Revolução Industrial, que ocorreu nos séculos XVIII e XIX, e que teve como principal particularidade a substituição do trabalho artesanal pelo trabalho assalariado e fabril, criou uma nova classe social: o proletariado.

Além desta nova classe social, também surgiu um novo modo de vida: as pessoas deixaram os campos e passaram a viver nas cidades, principalmente nos entornos das fábricas.

Este modelo de urbanização é bem evidente na atualidade, onde grandes centros se desenvolvem no entorno dos polos industriais do país. Sobre o tema Morais destaca:

\begin{abstract}
As diversas demandas relacionadas com o ambiente e a necessidade de uma atuação mais efetiva para evitar danos irreparáveis no futuro e, assim, antecipar possíveis quadros de extrema escassez e conflitos, acaba por sofrer as limitações dos mecanismos existentes, os quais não alcançam essa complexidade do conjunto da realidade atual de crise ambiental. (2018, p.15)
\end{abstract}

No Brasil a constatação é de que cada vez mais as pessoas têm fixado residência no entorno de grandes indústrias e no que toca às mineradoras, cidades se desenvolvem e se mantem exclusivamente com os recursos gerados pela extração mineral.

Sobre a urbanização no entorno de grandes mineradoras existem muitos riscos e é desaconselhável tal prática. Não é toda atividade industrial que pode se desenvolver em centros urbanos, existem atividades industriais que só podem se desenvolver longe das cidades, tendo em vista os potenciais riscos que acarretam às pessoas e ao meio ambiente.

Rezende e Silva abordaram o risco e meio ambiente:

É cediço que, no plano das questões afetas ao meio ambiente, vive-se em um contexto de crise e de risco caracterizado pela escassez dos recursos naturais e, ao mesmo tempo, pela infinitude de necessidades muitas vezes criadas nas quais se consubstancia uma relação desgastada e conflituosa entre homem e natureza. Diante deste cenário, o Direito deve interferir objetivando o alcance da coesão social e da proteção dos bens que lhe são mais caros. O artigo terceiro da Lei 6.938/81 define meio ambiente como "o conjunto de condições, leis, influências e interações de ordem física, química e biológica que permite, abriga e rege a vida em todas as suas formas." (Brasil, 1981) Assim, o direito ambiental pretende, de fato e de direito, a tutela da vida em todas as suas formas, contemplando as gerações presentes e as futuras. (2015, p.374)

A atividade de extração mineral além de degradar o meio ambiente, contribuir para o esgotamento dos recursos naturais, poluir e ainda causar a morte de seres vivos, deve ser analisada também como grande geradora de empregos e de receitas para o país. É uma atividade impulsionadora do desenvolvimento econômico e social do mundo. 
A mineração, como atividade extrativa, causa danos ao meio ambiente, mas é grande impulsionadora do desenvolvimento mundial, sendo certo que encontrar o ponto de equilíbrio entre desenvolvimento econômico e preservação ambiental constitui o cenário ideal.

Leite e Ayala destacam:

Por outro lado, é certo que não existe risco ambiental zero, pois qualquer atividade de utilização de recursos naturais, produção e desenvolvimento provoca danos e riscos. Além do que é correto afirmar que existe uma tolerância social e comunitária do risco e do dano ambiental, pois em sociedade convivemos com a lesividade e o risco ambiental permitido, como, por exemplo, o avião que polui e emana riscos ambientais, amparado por lei ou em face de decisão autorizativa de controle de gestão de riscos. (2015, p.47)

A grande questão que permeia várias discussões está em desenvolver alternativas que tornem viável o desenvolvimento da mineração, tão importante para a economia do Brasil e do mundo e a preservação ambiental, de suma importância para a sobrevivência da presente e das futuras gerações.

A globalização da vida em sociedade e de um modelo - capitalista - de economia condicionou a existência humana a uma certeza, ou seja, a da exclusão do futuro como consequência do habitar-morar no planeta. Por isso, a generalização da crise, como representação contemporânea da contradição entre a existência humana e a (existência/permanência) do meio natural apresenta, necessariamente, os traços de domínio-destruição do homem sobre a Terra". (MORAIS; SARAIVA, 2018, p.13)

A reestruturação do setor mineral brasileiro, depois do rompimento das barragens de Mariana (2015) e Brumadinho (2019), deverá passar por novos procedimentos empresariais, reavaliação da legislação afeta ao setor além de contemplar adequada destinação dos resíduos da mineração, que podem ser caracterizados como externalidades ambientais.

O planejamento de toda a cadeia produtiva deve contemplar desde a extração até o descarte dos rejeitos, não esquecendo de que o desenvolvimento sustentável inclui a preservação ambiental e o uso adequado dos recursos, sob pena de esgotamento, sanções legais e inviabilidade de sobrevivência das presentes e futuras gerações.

As Tragédias de Mariana e Brumadinho serviram para evidenciar que o Estado e os empresários precisam se unir para discutir o setor e colocar em prática alternativas, já existentes, para que esta atividade tão danosa possa conviver harmonicamente com o meio ambiente. 
A preservação ambiental e o desenvolvimento sustentável devem ser prioridade para toda a atividade econômica. Não existe desenvolvimento econômico desvencilhado do meio ambiente sendo importante destacar a grande importância da mineração no cenário econômico brasileiro.

\section{A IMPORTÂNCIA DA MINERAÇÃO NA ECONOMIA BRASILEIRA}

A relação desenvolvimento econômico versus preservação ambiental não tem sido equilibrada e constitui um dos principais problemas do Estado Moderno. Conciliar o desenvolvimento econômico com a proteção e a preservação do meio ambiente tem sido um desafio para o Poder Público principalmente na área de mineração.

Existem órgãos que cuidam especificamente do setor e cada qual na sua área de atuação, tentam absorver os impactos das tragédias de Mariana e Brumadinho.

O Instituto Brasileiro da Mineração (IBRAM) tem como atribuições representar a indústria mineral brasileira e trabalha de forma a congregar, promover e divulgar a mineração, além de contribuir para sua competitividade nacional e internacional.

Segundo dados do Instituto Brasileiro da Mineração (IBRAM), a mineração é um dos mais importantes setores da economia brasileira. É o setor que gera 180 mil empregos diretos, entre postos de trabalho diretos e indiretos são mais de 1 milhão, representa $4 \%$ do PIB, e é responsável por $25 \%$ do saldo comercial do país além de movimentar aproximadamente US\$ 50 bilhões por ano, valor que vem crescendo exponencialmente desde 2003.

Dados do IBRAM também apontam que a mineração cresce cerca de 5\% ao ano e atualmente existem cerca de 3 mil operações que ocupam $0,5 \%$ do território brasileiro e se distribuem em diversos estados do país.

Além disso, o Brasil ainda exporta vários produtos de origem mineral, tendo o minério de ferro como produto de maior representatividade, seja em volume (68\% das exportações são de minério de ferro) ou em valor (US\$ 19,2 bilhões em 2017 de uma exportação total do setor de US\$ 28,4 bilhões), segundo dados do Instituto Brasileiro da Mineração (IBRAM). 


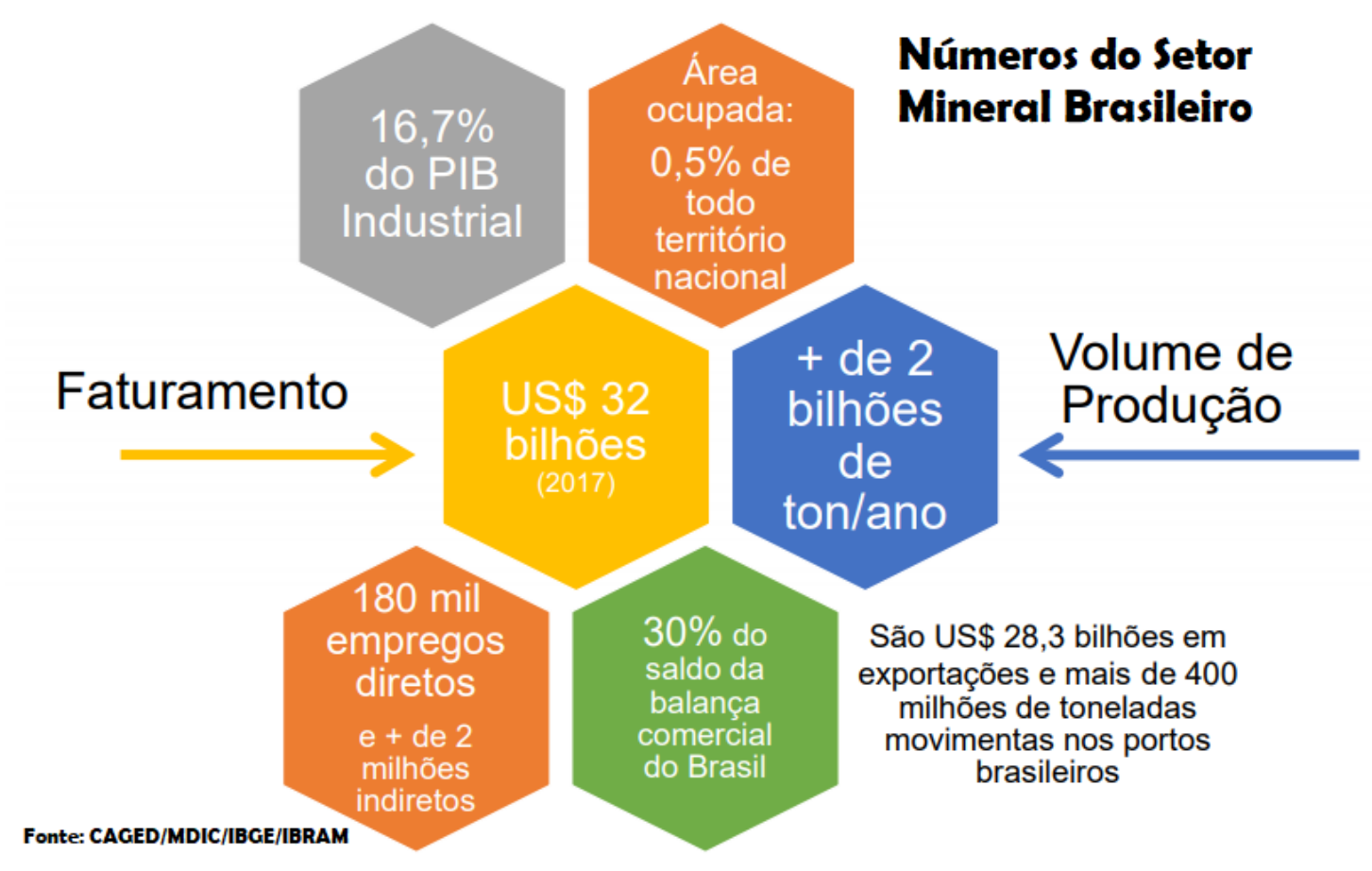

O tema mineração tem sido pauta de vários encontros e após a tragédia de Brumadinho (2019), o governador de Minas Gerais, Romeu Zema, já realizou várias declarações na imprensa.

As diversas declarações demostram que os órgãos públicos e privados envolvidos tem muito interesse em reformular o setor e que dispõem de recursos e processos para que a mineração se torne uma atividade segura e que possa se desenvolver harmonicamente com o meio ambiente.

Além de tudo o que foi dito destacamos a importância que a mineração tem para várias cidades e estados do país que sobrevivem com os recursos gerados pela extração principalmente do minério de ferro. A paralisação do setor além de afetar diretamente estas comunidades também poderá acarretar reflexos em outros setores, como por exemplo, o de fertilizantes que consequentemente pode refletir negativamente na produção de alimentos.

Vale destacar que quando falamos em desenvolvimento, economia, produção, estamos falando em uma cadeia produtiva interdependente de atividades, onde uma atividade depende da outra, que também refletem no consumo. 
É temerário falar só em economia, o correto é a referência a um desenvolvimento economicosocial do país, uma vez que os setores são interdependentes e se alimentam uns dos outros. Um exemplo disso são as construções de ferrovias, minerodutos, portos, além de concessões territoriais que decorrem da atividade mineral e que beneficiam vários setores da sociedade.

O Poder Público também desempenha importante papel na adequada regulamentação e fiscalização da mineração, sendo responsável pela reparação dos danos causados ao meio ambiente seja em face de ação ou omissão, o que será visto no próximo capítulo.

\section{DA RESPONSABILIDAde CIVIL AMBIENTAL DO PODER PÚBLICO NA MINERAÇÃO}

A responsabilidade civil consiste na obrigação de reparar os danos causados, seja no âmbito patrimonial ou moral. No que toca ao Estado, doutrina e jurisprudência admitem que a responsabilidade é objetiva, ou seja, a que independe da comprovação de dolo ou de culpa do Estado, e está prevista no parágrafo $6^{\circ}$ do artigo 37 da Constituição Federal. Tal conceito também é aplicado no caso da responsabilidade civil por danos ao meio ambiente.

Art. 37, § $6^{\circ}$ - As pessoas jurídicas de direito público e as de direito privado prestadoras de serviços públicos responderão pelos danos que seus agentes, nessa qualidade, causarem a terceiros, assegurado o direito de regresso contra o responsável nos casos de dolo ou culpa. (BRASIL, 1988)

As tragédias de Mariana/MG e Brumadinho/MG contribuíram para dar visibilidade à grande desídia estatal em exercer o seu papel. Foram necessárias mais de 300 mortes, a destruição de rios e extensa área de mata atlântica, para que se chegassem à conclusão de que existem fragilidades na governança, na capacidade de fiscalização, no planejamento e na resposta a crises.

A mineração, setor de suma importância para o desenvolvimento econômico e social do país, não pode ter tratamento tão displicente e irresponsável. O Poder Público precisa adotar postura ativa na regulamentação e fiscalização adequadas do setor sob pena de também ser responsabilizado civilmente por sua desídia. 
Hoje o Estado não é visto mais como “irresponsável” ou "inatingível”, e sobre a responsabilidade civil do Poder Público destacamos o julgado do STF, relator Ministro Celso de Mello:

\begin{abstract}
Como se sabe, a teoria do risco administrativo, consagrada em sucessivos documentos constitucionais brasileiros, desde a Carta Política de 1946, revela-se fundamento de ordem doutrinária subjacente à norma de direito positivo que instituiu, em nosso sistema jurídico, a responsabilidade civil objetiva do Poder Público, pelos danos que seus agentes, nessa qualidade, causarem a terceiros, por ação ou por omissão (CF, art. $\left.37, \S 6^{\circ}\right)$. Informada pela 'teoria do risco', a responsabilidade do Estado apresenta-se hoje, na maioria dos ordenamentos, como 'responsabilidade objetiva'. Nessa linha, não mais se invoca o dolo ou culpa do agente, o mau funcionamento ou falha da Administração. Necessário se torna existir relação de causa e efeito entre ação ou omissão administrativa e dano sofrido pela vítima. É o chamado nexo causal ou nexo de causalidade. Deixa-se de lado, para fins de ressarcimento do dano, o questionamento do dolo ou culpa do agente, o questionamento da licitude ou ilicitude da conduta, o questionamento do bom ou mau funcionamento da Administração. Demonstrado o nexo de causalidade, o Estado deve ressarcir. (STF - AI 734689 AgRED)
\end{abstract}

No que tange a responsabilidade civil ambiental nos eventos de Mariana/MG e Brumadinho/MG destacamos posicionamento de Antunes:

\begin{abstract}
Há ainda a responsabilidade civil por indenizar e reparar as vítimas e seus familiares, com valores pecuniários medidos de acordo com o prejuízo comprovado, bem como por um montante compensatório a ser arbitrado judicialmente. Trata-se de responsabilidade objetiva, que independe da comprovação de dolo ou culpa em sentido estrito. Também se extrai a evidente responsabilidade civil ambiental pelos danos causados ao meio ambiente, na qual a Vale responde objetivamente e ainda pelo risco integral, o que significa que não pode alegar as excludentes de responsabilidade (fato de terceiro, fato da vítima e caso fortuito e força maior) como forma de não ser responsabilizada. (2012, p.25)
\end{abstract}

Cabe destacar que após o rompimento das barragens mineiras o Poder Público já adotou as seguintes posturas no que toca à mineração: III) Resolução $n^{\circ} 2$, de 28 de janeiro de 2019, da Agência Nacional de Mineração (ANM), que instituiu o Subcomitê de elaboração e atualização legislativa, com o objetivo de elaborar anteprojeto de atualização e revisão da Política Nacional de Segurança de Barragens, estabelecida pela Lei $n^{\circ} 12.334$, de 20 de setembro de 2010; II) Resolução n 4 de 15 de fevereiro de 2019, da Agência Nacional de Mineração (ANM), que estabelece medidas regulatórias cautelares objetivando assegurar a estabilidade de barragens de mineração, notadamente aquelas construídas ou alteadas pelo método denominado "a montante" ou por método declarado como desconhecido; III) criação em 2017 da Agência Nacional de Mineração (ANM) do governo federal, que substituiu o 
Departamento Nacional de Produção Mineral (DNPM) e é responsável pelas políticas regulatórias do setor mineral; IV) Criação, também em 2017, do Sistema Integrado de Gestão de Segurança de Barragens de Mineração (SIGBM), responsável por gerir informações sobre as barragens instaladas pelo Brasil; IV) Lei 12.334/2010, que estabelece a Política Nacional de Segurança de Barragens; V) Portaria DNPM n 416/12, que exige da exploradora de minério inspeções quinzenais nas barragens e a Declaração de Estabilidade da Barragem.

Especialistas do setor apontam que a grande fragilidade da mineração está na gestão dos resíduos, que foram os grandes responsáveis pelas tragédias de Mariana/MG e Brumadinho/MG.

Comprovadamente existem métodos de extração mineral sem a utilização de barragens de rejeitos, mas são considerados caros pelos empresários do setor e alguns chegam a afirmar que inviabilizaria o negócio. Mas a simples avaliação da lucratividade de um empreendimento não esgota toda a temática que abrange a mineração.

Segundo o Instituto de Terras, Cartografia e Geologia do Paraná-ITCG:

\begin{abstract}
A imagem da mineração como uma atividade agressiva ao meio ambiente e aos interesses do desenvolvimento sustentado tem suas raízes na intensa demanda pelos bens minerais que vigorou no passado, associada à falta tanto, de soluções tecnológicas adequadas, quanto de prioridade para a conservação ambiental na agenda dos governos. Esta combinação de fatores induziu o desenvolvimento de uma indústria mineral predatória, bastante generalizada no Brasil até épocas recentes da nossa história.( 2018)
\end{abstract}

A análise da responsabilidade civil do Estado e dos empresários deve ser melhor avaliada, fiscalizada e ter resposta imediata do Poder Judiciário quando ocorrerem os eventos danosos ao meio ambiente.

O estudo sobre Responsabilidade Civil por danos ao meio ambiente no Brasil vem se
consolidando há muitos anos, mormente com o advento da Lei $6.938 / 81$ que
introduziu no ordenamento jurídico a denominada "Política Nacional de Meio
Ambiente" dispondo sobre os fins e mecanismos de formulação e aplicação de todo
um conjunto de princípios, regras e normas que são postos às autoridades e à
sociedade para que providenciem a melhor tutela do bem ambiental. No artigo 14, § $1^{\circ}$,
dessa lei, estabeleceu-se, inexoravelmente, que a Responsabilidade Civil por Danos
Ambientais é objetiva, isto é, independe da demonstração de culpa daquele que por
um comportamento positivo ou negativo, degradou o meio ambiente. (REZENDE;
BIZAWU, 2013. p. 16)

A Lei 13.575 de 26/12/2017, que criou a Agência Nacional de Mineração /ANM), vinculada ao Ministério das Minas e Energia dispõe em seu artigo $2^{\circ}$ : 
Art. $2^{\circ}$ A ANM, no exercício de suas competências, observará e implementará as orientações e diretrizes fixadas no Decreto-Lei $n^{\circ} 227$, de 28 de fevereiro de 1967 (Código de Mineração), em legislação correlata e nas políticas estabelecidas pelo Ministério de Minas e Energia, e terá como finalidade promover a gestão dos recursos minerais da União, bem como a regulação e a fiscalização das atividades para o aproveitamento dos recursos minerais no País, competindo-lhe:

I - implementar a política nacional para as atividades de mineração;

II - estabelecer normas e padrões para o aproveitamento dos recursos minerais, observadas as políticas de planejamento setorial definidas pelo Ministério de Minas e Energia e as melhores práticas da indústria de mineração;

VIII - regulamentar os processos administrativos sob sua competência, notadamente os relacionados com a outorga de títulos minerários, com a fiscalização de atividades de mineração e aplicação de sanções;

XI - fiscalizar a atividade de mineração, podendo realizar vistorias, notificar, autuar infratores, adotar medidas acautelatórias como de interdição e paralisação, impor as sanções cabíveis, firmar termo de ajustamento de conduta, constituir e cobrar os créditos delas decorrentes, bem como comunicar aos órgãos competentes a eventual ocorrência de infração, quando for o caso;

XV - decidir sobre direitos minerários e outros requerimentos em procedimentos administrativos de outorga ou de fiscalização da atividade de mineração, observado o disposto no art. $3^{\circ}$ desta Lei;

XXII - estabelecer normas e exercer fiscalização, em caráter complementar, sobre controle ambiental, higiene e segurança das atividades de mineração, atuando em articulação com os demais órgãos responsáveis pelo meio ambiente e pela higiene, segurança e saúde ocupacional dos trabalhadores;

XXIII - definir e disciplinar os conceitos técnicos aplicáveis ao setor de mineração;

XXIX - normatizar e reprimir as infrações à legislação e aplicar as sanções cabíveis, observado o disposto nesta Lei. (BRASIL, 2017)

Da análise da legislação acima extrai-se que cabe ao Poder Público a "fiscalização de atividades de mineração e aplicação de sanções" e no caso de omissão poderá ser responsabilizado civilmente por sua inércia em desempenhar papel legalmente previsto.

No que toca a escolha de políticas públicas Dworkin se manifesta: ${ }^{3}$

Policy arguments justify a political decision demonstrating that this decision promotes or protects some goal of the community as a whole. The argument in favor of the subsidy for producers of airplanes, on the grounds that the subsidy will serve for national security, is a policy argument. Arguments of principles justify a political decision demonstrating that this decision respects or secures some individual or group right. The argument in favor of anti-discriminatory statutes, which a minority has the right to equal respect and treatment, is an argument of principle. $(1999$, p. 82)

\footnotetext{
${ }^{3}$ Argumentos de política justificam uma decisão política demonstrando que esta decisão promove ou protege algum objetivo da comunidade como um todo. O argumento em favor do subsídio para produtores de aviões, com o argumento de que o subsídio servirá para a segurança nacional, é um argumento de política. Argumentos de princípios justificam uma decisão política demonstrando que esta decisão respeita ou assegura algum direito individual ou de grupo. $\mathrm{O}$ argumento em favor de estatutos antidiscriminatórios, de que uma minoria tem o direito a igual respeito e tratamento, é um argumento de princípio. (Dworkin, 1999, p.82)
} 
O tratamento adequado das "externalidades" da atividade minerária e que estão sendo classificadas como as grandes causas de alguns dos maiores desastres sociais e ambientais do planeta devem ser prontamente tratadas pelo Poder Público e pela classe empresária de forma preventiva. As tragédias de Mariana/MG e Brumadinho/MG foram responsáveis pela poluição e degradação da $5^{\text {a }}$ maior bacia hidrográfica do país e de áreas de intensa biodiversidade na costa atlântica brasileira, além de causar a morte de mais de 300 pessoas e de várias espécies da flora e fauna da região.

As medidas adotadas para tratar as tragédias de Mariana/MG e Brumadinho/MG foram insuficientes para sanar/minimizar a extensão dos problemas gerados. Várias ações em trâmite nas Justiças Estadual e Federal e nenhum responsável punido, o meio ambiente não foi recuperado, as indenizações não foram direcionadas para as ações necessárias, todas as vítimas não foram identificadas e indenizadas, o dano ambiental não foi mensurado, o que demostra que a legislação brasileira está muito aquém do que deveria ser, principalmente no que toca à responsabilidade civil do Estado por sua ação ou omissão.

A mineração, um setor de grande importância para a economia do Brasil e do mundo, não pode mais ser tratado de forma tão displicente. Os resíduos da mineração não podem mais ser jogados em barragens e ali permanecerem por anos até que ocorra uma tragédia que cause grave dano ao meio ambiente, para a partir deste ponto implementar medidas para regulamentar e fiscalizar o setor.

O modelo existente não é adequado, o setor precisa de uma reestruturação urgente, para que possa se desenvolver em harmonia com o meio ambiente. A responsabilização civil, penal e administrativa precisa ser eficiente e deve existir medidas preventivas para evitar as crises e uma fiscalização adequada e eficiente para que tragédias não voltem a ocorrer.

Especialmente no que tange à responsabilidade civil, resposta atribuída a uma conduta
lesiva e danosa ao meio ambiente, tem-se a cominação das indenizações de caráter
compensatório e reparatório. Tal instituto ainda assume postura preventiva,
sustentada, sobretudo, juridicamente pelos princípios do poluidor-pagador, da
prevenção e precaução. (REZENDE; SILVA, 2015, p.375)

Como em países como Chile e Peru, as barragens devem ser proibidas no Brasil e novos modelos de beneficiamento mineral adotados compulsoriamente, mesmo que mais onerosos para os empresários. Comprovadamente estes métodos já trazem um grande 
benefício ao meio ambiente já que não utilizam água no processo de beneficiamento mineral, e a água é um recurso natural classificado como escasso.

Também, especialistas já afirmaram que as novas tecnologias de beneficiamento a seco, embora mais onerosas no início, se tornam bem vantajosas a longo prazo, uma vez que utilizam menos insumos químicos e água, além de aproveitarem maior quantidade de minério que, por se apresentar em partículas menores, seria descartado nas barragens.

A análise dos modelos tradicionais de barragens de rejeitos demonstra toda a fragilidade do setor e o grande risco humano e ambiental que a permanência deste modelo pode gerar, sendo relevante avaliar os métodos ambientalmente mais adequados e disponíveis no mercado.

\section{MODELOS DE BARRAGENS DE REJEITOS E SUAS CARACTERÍSTICAS}

As recentes tragédias que envolveram a mineração no Brasil estão ligadas ao modelo de descarte de rejeitos, ou seja, a gestão dos resíduos chamados de externalidades.

Para obter o maior lucro possível com a mineração os empresários têm utilizado meios de extração com o menor custo, o que tem gerado grandes tragédias ambientais e sociais. Vale a máxima de que os fins justificam os meios e que vale a pena correr o risco da ocorrência do evento danoso, pois os lucros são compensadores.

O planejamento de risco para a manutenção e construção de barragens deve levar em conta além dos custos as condições climáticas do local, que determinarão a escolha do melhor modelo.

As barragens são grandes estruturas para dispor materiais. Se parecem com grandes piscinas onde os rejeitos misturados com água são depositados. Parte da água evapora e a parte sólida e mais pesada decanta. Os modelos de barragens existentes e mais comuns são:

O método conhecido como barragem por "alteamento a montante" é aquele no qual os rejeitos são depositados em "piscinões" e a barreira de contenção recebe camadas do próprio material, formando degraus que vão sendo elevados exatamente acima do anterior, o que torna a barragem menos segura. Era o modelo adotado nas minas Córrego do Feijão em Brumadinho/MG e Fundão em Mariana/MG. Como vantagens para a escolha deste modelo 
destaca-se: menor custo, maior rapidez na construção e melhor aproveitamento da área. Como desvantagens: maior probabilidade de ruptura, maior instabilidade e sensibilidade a abalos sísmicos e dificuldade de implementação de sistema de drenagem eficiente.

A barragem por alteamento a jusante é aquela onde cada alteamento é estruturalmente independente da disposição dos rejeitos. Ela é mais segura já que não forma degraus acima dos rejeitos e sim uma pirâmide. Como pontos positivos destaca-se a menor probabilidade de ruptura interna, maior compactação do material depositado, sistema de drenagem. Os pontos negativos são: custo elevado e necessidade de uma maior área de construção.

Já as barragens de linha de centro mesclam as técnicas a montante e a jusante, e apresentam tanto degraus quanto o caimento para fora (pirâmide). Este caimento torna a estrutura mais segura que a de montante. Porém, ainda é menos segura que o modelo à jusante. As vantagens são: melhor aproveitamento do espaço físico e drenagem eficiente. As desvantagens são: possibilidade de ocorrência de fissuras internas na barragem e custo

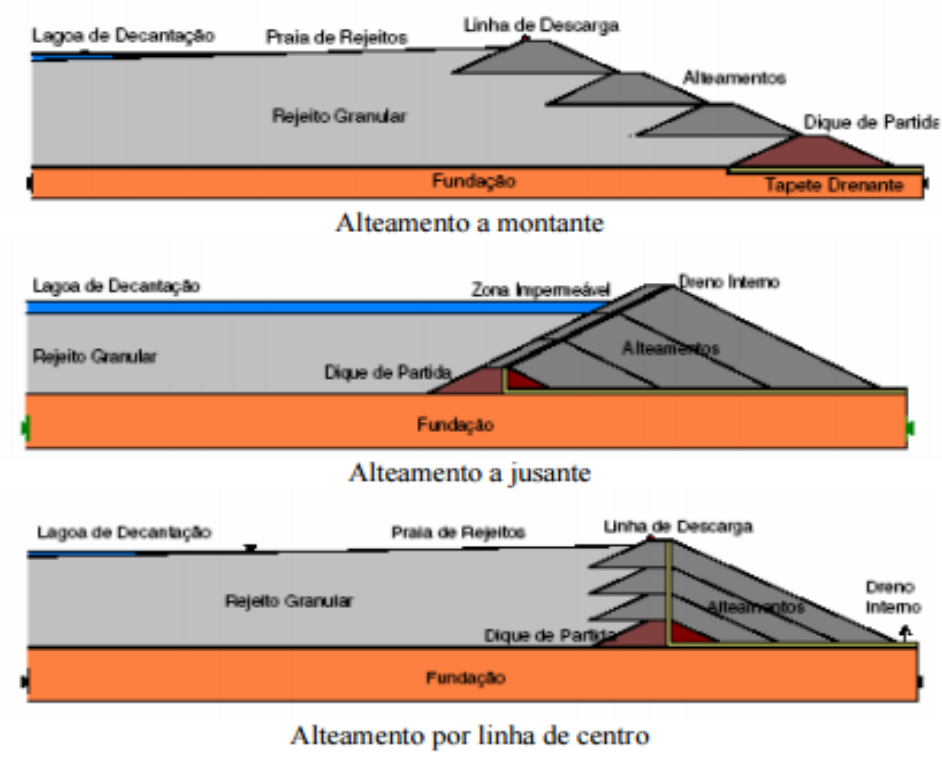

elevado.

Figura 1 - Métodos construtivos de barragens de rejeito (Araújo, 2006)

A adoção de modelos que não utilizam barragens para o depósito de rejeitos constitui o cenário ideal e que promove menores riscos de danos ao meio ambiente. A denominada "mineração a seco" se apresenta como uma das soluções para o mercado e para o meio ambiente. 


\section{MINERAÇÃO A SECO E REAPROVEITAMENTO DOS REJEITOS COMO SOLUÇÃO PARA O IMPASSE ENTRE MINERAÇÃO E PRESERVAÇÃO AMBIENTAL}

O rompimento das barragens em Mariana/MG e Brumadinho/MG evidenciaram que a sustentabilidade e a gestão responsável e efetiva devem ser vistas como prioridades no setor de mineração. Já existem no mercado técnicas de beneficiamento mineral que não utilizam as barragens de rejeitos, consideradas as grandes vilãs e responsáveis pelas maiores tragédias ambientais do país.

As alternativas disponíveis em substituição às barragens de rejeitos são:

- Armazenagem a seco de rejeitos minerais (tecnologia de disposição de rejeito a seco - dry stacking): Esta técnica consiste num processo de filtragem e secagem dos rejeitos que ficam armazenados em silos ou pilhas. Técnica de custo elevado e que requer grandes espaços para armazenar os resíduos que podem ou não ser reaproveitados para outras finalidades como a fabricação de tijolos. Vale destacar que o processo do beneficiamento do minério utiliza grande quantidade de água e esta técnica se difere da tradicional apenas na secagem dos rejeitos que seriam depositados nas barragens. Causa grande impacto ambiental, pois os rejeitos secos formam grandes pilhas de poluentes que se espalham facilmente pelo ambiente através do ar. Como vantagem destacamos a possibilidade de reaproveitamento de até $95 \%$ da água utilizada no beneficiamento do minério e permite que as áreas tratadas recuperem sua fauna e flora nativa.

- Beneficiamento a seco do minério de ferro: Consiste no processamento do minério de ferro sem utilização de água, neste processo utiliza-se a própria umidade do material que passa por várias etapas de britagem e peneiramento. Os rejeitos são secos e armazenados em pilhas, silos ou utilizados para outros fins. As barragens são inexistentes e desnecessárias. Como vantagem, além da economia de água, este método preserva as partículas mais finas de minério que seriam descartadas nas barragens e que passam a fazer parte do processo e se tornam lucro para a empresa. É o modelo utilizado pela Vale S/A em sua planta S11D em Carajás/PA.

O diretor da Ourominas Juarez Filho destaca que o mercado brasileiro já possui uma tecnologia de mineração a seco que foi idealizada por ele e denominada "Eco Gold System 
Joares", que não utiliza água no processo de separação do ouro e cobre e dispensa a utilização de produtos químicos como mercúrio e cianeto, o que impede possíveis contaminações no solo, além de grande economia de água.

A construção de barragens de rejeitos é uma escolha do empreendedor, pois existem alternativas mais adequadas, benéficas ao meio ambiente e também lucrativas. A preservação ambiental para a presente e futuras gerações não é mera liberalidade. As empresas do setor precisam revisar todo o processo produtivo, as tecnologias empregadas na disposição dos rejeitos e evoluir de forma sustentável e socialmente responsável.

\section{CONCLUSÕES}

O rompimento das barragens de Mariana/MG em 2015 e Brumadinho/MG em 2019 mostraram ao mundo a fragilidade da mineração no Brasil e a grande necessidade de mudar padrões tanto legais quanto técnicos.

Os danos ao meio ambiente são de difícil mensuração, muitos mortos e um passivo social ainda em avaliação pelo poder público. Ações judiciais sem uma possível solução a curto prazo. Órgãos do Executivo, Legislativo e Judiciário em conflito na busca de responsáveis e indenizações. Este foi o legado deixado pela negligência das empresas do setor mineral que não trataram adequadamente os rejeitos da mineração e pelo Poder Público que não cumpriu com o seu dever de fiscalizar.

A avaliação que pode ser feita é de que o atual modelo faliu. O setor terá que passar por uma reformulação em toda a sua cadeia produtiva principalmente na gestão dos resíduos que não podem mais ser depositados em barragens. Mesmo que consideradas mais onerosas, as novas tecnologias de tratamento dos resíduos devem ser de adoção compulsória para o bem de toda a humanidade. Os fins não podem ser justificativa para meios ambientalmente e socialmente inadequados.

Mesmo que mais onerosa em um primeiro momento as novas tecnologias se tornam adequadas e econômicas se analisados todos os custos envolvidos com o rompimento de uma barragem e com a recomposição dos danos ambientais. A adoção do sistema de beneficiamento a seco corresponde a um investimento em sustentabilidade e em mitigação de riscos. 
No caso de uma tragédia, como as de Mariana/MG e Brumadinho/MG, o valor das multas, indenizações e reparação dos danos ambientais são muito superiores a qualquer modelo de beneficiamento a seco. Somado a tudo isso o passivo ambiental a que as barragens estão expostas. A conclusão de especialistas é a de que, mesmo sendo um processo oneroso no início, depois o beneficiamento a seco se torna compensatório.

Diante de todo este cenário, a economia terá que se ajustar aos novos padrões sob pena de comprometer as futuras gerações que não poderão mais sobreviver nestes ambientes.

Como resposta ao problema formulado e às questões atinentes ao tema central do presente estudo a conclusão é de que por serem concessões governamentais, as mineradoras devem ser fiscalizadas e deverá ser exigido o uso dos recursos de maneira racional. O desenvolvimento do plano de fechamento das minas deverá começar no primeiro ano de operação e não somente no fim da extração.

O meio ambiente deverá ser recomposto o quanto antes de forma a minimizar os impactos ambientais e a preservação das espécies. O assunto é importante porque o passivo tóxico da mineração tradicional pode afetar gerações se não tratado preventivamente.

O Poder Público terá que adotar novos modelos de gestão e fiscalização de toda a cadeia produtiva. A capacitação de agentes públicos deverá ser constante e contemplar servidores de todas as esferas, além de dotar os órgãos da tecnologia necessária para o adequado desempenho das funções.

Caberá ao Poder Legislativo a revisão da legislação afeta ao setor e a adoção de todas as medidas necessárias para que existam leis claras e específicas ao setor. Conceitos abertos, conflito de competência entre os entes federados e a ausência de sanções em caso de descumprimento de normas são inaceitáveis.

Caberá ao Poder Judiciário capacitar seus servidores para que possam julgar adequadamente as questões afetas ao meio ambiente e com agilidade. O meio ambiente não pode ser exposto a riscos desnecessários e a demora na solução dos conflitos pode agravar as perdas, gerar a extinção de mais espécies, o esgotamento de recursos, mais poluição ou a morte de pessoas.

Conclui-se que a mineração é uma atividade econômica muito lesiva ao meio ambiente, mas de suma importância para o desenvolvimento econômico e social das nações. Muitos produtos que estão em todas as casas têm como matéria prima o minério de ferro. A 
sobrevivência sem a mineração é inimaginável e, é por este motivo que a atividade de extração mineral deve seguir rigorosos padrões de sustentabilidade que conciliem mineração com a mínima agressão ao meio ambiente. Este desafio é possível de ser atingido com a adoção de novos métodos de beneficiamento mineral a seco e com o reaproveitamento dos rejeitos para a fabricação de tijolos e outros subprodutos.

\section{REFERÊNCIAS}

ANTUNES, Paulo de Bessa. Direito ambiental. 14. ed. São Paulo: Atlas, 2012.

BECK, Ulrich. La sociedade del riesgo: hacia una nueva modernidad. Tradução por Jorge Navarro, Daniel Jiménez e Ma. Rosa Borrás. Barcelona: Paidós, 1998.

BRASIL. Congresso Nacional. Lei Federal 6.938, de 31 de agosto de 1981. Dispõe sobre a Política Nacional do Meio Ambiente, seus fins e mecanismos de formulação e aplicação, e dá outras providências. Disponível em: http://www.planalto.gov.br/ccivil_03/leis/16938.htm. Acesso em: 20 de março de 2019.

BRASIL. Congresso Nacional. Congresso Nacional. Lei Federal nº 9.605, de 12 de fevereiro de 1998. Dispõe sobre as sanções penais e administrativas derivadas de condutas e atividades lesivas ao meio ambiente, e dá outras providências. Disponível em:

http://www.planalto.gov.br/ccivil_03/Leis/L9605.htm. Acesso em: 20 de março de 2019.

CASTRO, Lucas Siqueira; ALMEIDA, Eduardo Simões. Desastres e desempenho econômico: avaliação do impacto do rompimento da barragem de Mariana. Geosul, Florianópolis, v. 34, n. 70, p. 406-429 (2019).

Disponível em: https://periodicos.ufsc.br/index.php/geosul/article/view/2177-

5230.2019v34n70p406. Acesso em: 06 mai. 2019.

COELHO, Fábio Ulhoa. Curso de Direito Comercial - direito de empresa. Volume 2. 15.

Ed. São Paulo. Editora Saraiva, 2011.

DWORKIN, Ronald. Império do direito. São Paulo: M. Fontes, 1999.

DWORKIN, Ronald. Uma questão de princípio. 2. ed. São Paulo: Martins Fontes, 2005. FARIAS, Cristiano Chaves de; ROSENVALD, Nelson. Direito Civil - teoria geral. $6^{\text {a }}$ ed. Rio de Janeiro. Editora Lumen Juris. 2007.

HENRÍQUEZ, Maria Amélia. Mineração maldição ou dádiva - Os dilemas do desenvolvimento sustentável a partir de uma base mineira. São Paulo: Signus, 2008. 
LEITE, José Rubens Morato; AYALA, Patryck de Araújo. Dano Ambiental: Do individual ao coletivo extrapatrimonial. Teoria e Prática. 7. ed. São Paulo: Revista dos Tribunais, 2015.

MACHADO, Paulo Affonso Leme. Direito Ambiental brasileiro. 26.ed. Malheiros: São São Paulo, 2018.

MILARÉ, Édis. Direito do ambiente: a gestão ambiental em foco: doutrina, jurisprudência, glossário. 7. ed. rev., atual e reform. São Paulo: Revista dos Tribunais, 2011. MORAIS, José Luis Bolzan de. O Estado e suas crises. Porto Alegre: Livraria do Advogado, 2005.

MORAIS, Jose Luis Bolzan de; SARAIVA, Bruno Cozza. O estado de direito socioambiental como condição de possibilidade destinada à tutela. Veredas do Direito, Belo Horizonte, v. 15, n. 32, p.11-37, maio/agosto 2018. Disponível em:

http://www.domhelder.edu.br/revista/index.php/veredas/article/view/1159/24593. Acesso em: 02 de maio de 2019.

REZENDE, Elcio Nacur; BIZAWU, Kiwonghi. Responsabilidade civil por danos ambientais no Brasil e em Angola: Um Estudo Panorâmico Comparado da Teoria do Risco Criado versus A Teoria do Risco Integral nos Ordenamentos Positivados do Brasil e Angola. 2013. XXII Encontro Nacional do CONPEDI / UNINOVE Tema: Sociedade global e seus impactos sobre o estudo e a efetividade do Direito na contemporaneidade de 13 a 16 de novembro de 2013 Universidade Nove de Julho - UNINOVE / São Paulo, - SP. Disponível em:

http://www.publicadireito.com.br/publicacao/uninove/livro.php?gt=162. Acesso em: 25 de março de 2019.

REZENDE, Élcio Nacur; SILVA, Larissa Gabrielle Braga e. Vida não tem preço: punitive damage e responsabilidade civil ambiental no ordenamento jurídico brasileiro. Revista Thesis Juris, [s.1.], v. 4, n. 2, p.373-390, 1 ago. 2015. Universidade Nove de Julho.

http://dx.doi.org/10.5585/rtj.v4i2.262. Disponível em:

http://www.revistartj.org.br/ojs/index.php/rtj/article/view/262. Acesso em: 10 de março de 2019.

RIBEIRO, Maísa de Souza; TOLEDO JÚNIOR, Márcio da Silva. Os efeitos econômicos do rompimento de barragem de resíduos: divulgações nas demonstrações contábeis comparativamente à grande mídia. Rev. Adm. UFSM, Santa Maria, v. 10, Ed. Especial, p. 100-116, 2017. Disponível em: https://periodicos.ufsm.br/reaufsm/article/view/25338. Acesso em: 06 mai. 2019.

TOLEDO, André de Paiva; RIBEIRO, José Cláudio Junqueira; THOMÉ, Romeu. Acidentes com Barragens de Rejeitos da Mineração e o Princípio da Prevenção - De Trento (Itália) a Mariana (Brasil). Rio de Janeiro: Lumen Juris, 2016. 